\title{
Functional Capillary Density Decreases after the First Week of Life in Term Neonates
}

\author{
A.P.C. Top ${ }^{a, c}$ M. van Dijk ${ }^{a} \quad$ J.E. van Velzen ${ }^{a} \quad$ C. Ince $^{b} \quad$ D. Tibboel ${ }^{a}$ \\ a Department of Pediatric Surgery, Erasmus MC-Sophia Children's Hospital, and ' ${ }^{\mathrm{b}}$ Department of Intensive Care, \\ Erasmus MC, Rotterdam, The Netherlands; ' ${ }^{C}$ Department of Pediatric Intensive Care, Addenbrooke's Hospital, \\ Cambridge, UK
}

\section{Key Words}

Microcirculation · Functional capillary density · Orthogonal polarization spectral imaging

\begin{abstract}
Background: Changes in the microcirculation have been recognized to play a crucial role in many disease processes. In premature neonates, functional capillary density (FCD) decreases during the first months of life. Objectives: The aims of this study were to obtain microcirculatory parameters in term neonates and older children who did not present with compromised respiration or circulation and to determine developmental changes in the microcirculation in young children. Methods: This single-center prospective observational study was performed at a level III university children's hospital. Subjects eligible for inclusion were children up to the age of 3 years who did not have any respiratory compromise, circulatory compromise or signs of dehydration. The buccal mucosa of 45 children was assessed, using orthogonal polarization spectral imaging. Results: We found a significantly higher FCD in neonates younger than 1 week compared with older children. The median FCD was 8.1 $\mathrm{cm} / \mathrm{cm}^{2}$ (range 7.3-9.4) for 0- to 7-day-old neonates $(\mathrm{n}=12$ ), $6.9 \mathrm{~cm} / \mathrm{cm}^{2}$ (range 4.7-8.7) for 8- to 28-day-olds $(n=10), 7.3$
\end{abstract}

$\mathrm{cm} / \mathrm{cm}^{2}$ (range 6.1-8.8) for 1- to 6-month-olds $(\mathrm{n}=19)$ and $6.7 \mathrm{~cm} / \mathrm{cm}^{2}$ (range 6.5-9.2) for 3-year-olds ( $\mathrm{n}=4$ ). After the first week, there was no significant correlation between age and FCD. Conclusion: FCD of the buccal mucosa decreases after the first week of life.

Copyright $\odot 2010$ S. Karger AG, Basel

\section{Introduction}

Microcirculation plays a crucial role in the interaction between blood and tissue in both physiological and pathophysiological states. The analysis of microvascular blood flow alterations gives a unique perspective to study disease processes at the microscopic level [1]. Measurement of tissue perfusion is of great importance in intensive care medicine, mostly because critically ill patients with abnormal tissue perfusion may develop multiple organ failure, a complication associated with high morbidity and mortality. Macrocirculatory parameters such as blood pressure, heart rate and hemoglobin oxygen saturation are rather insensitive markers of tissue perfusion [2].

A variety of techniques have been used to assess the microcirculation of critically ill patients. Orthogonal po-

\section{KARGER \\ Fax +41613061234 E-Mail karger@karger.ch} www.karger.com (c) 2010 S. Karger AG, Basel 1661-7800/11/0991-0073\$39.00/0

Accessible online at: www.karger.com/neo
Anke P.C. Top, MD

Pediatric Intensive Care Unit, Addenbrooke's Hospital, Box 7

Hills Road

Cambridge CB2 0QQ (UK)

Tel. +44 1223586 795, Fax +44 1223586 794, E-Mail anke.top@ addenbrookes.nhs.uk 
larization spectral (OPS) imaging is a technique for bedside visualization of the microcirculation in which polarized light illuminates the area of interest, is reflected by the background, and is absorbed by the hemoglobin $(\mathrm{Hb})$ of the flowing red blood cells in the microcirculation [3]. Specific optic filtration allows the elimination of light reflected at the surface of the tissue to produce highcontrast reflected light images of the microcirculation. Therefore, in contrast to conventional intravital microscopy, there is no need to inject contrast or fluorescent dyes. This technique is safe, noninvasive and allows imaging of mucous membranes and surfaces of solid organs. The introduction of OPS imaging to clinical medicine has opened a new field of monitoring the microcirculation for the investigation of the pathophysiological processes of various disease states [4].

The OPS imaging technique has been applied in adults in various clinical settings, mainly in sepsis. Little is known about the microcirculation in children and infants. A few studies in newborns and infants have used videophotometric microscopy or laser Doppler to evaluate blood cell velocity in the nailfold capillaries of the thumb $[5,6]$. More recently, the group of Genzel-Boroviczeny applied OPS imaging in premature and term infants to study the microvascular perfusion of the skin $[7,8]$. This transdermal application of OPS imaging proved useful in premature infants as a noninvasive procedure and provided quantitative data of microvascular diameter and red blood cell velocity. The functional capillary density (FCD) in the skin of premature infants decreased significantly over the first month of life and correlated with decreases in $\mathrm{Hb}$ and incubator temperature [7].

We published data on the buccal microcirculation in critically ill neonates [8]. Most research in adults is done in the sublingual region. This region is difficult or impossible to access in younger children because of the size of the probe, and measurements in this area are not as well tolerated. In children above the neonatal age, the quality of transcutaneous measurements is poor because the skin is thicker. The vasculature of the skin is also influenced by environmental factors such as temperature [9]. The skin microcirculation has a specific function, namely thermoregulation. This function is not shared by other microcirculatory beds, which limits generality. In this study, the buccal mucosa was chosen as the site of investigation for several reasons. It shares a similar embryonic origin with the splanchnic mucosa, making it a relevant bed to study in pathological conditions [10]. It is readily accessible and has become an important site for microcirculatory studies [2].

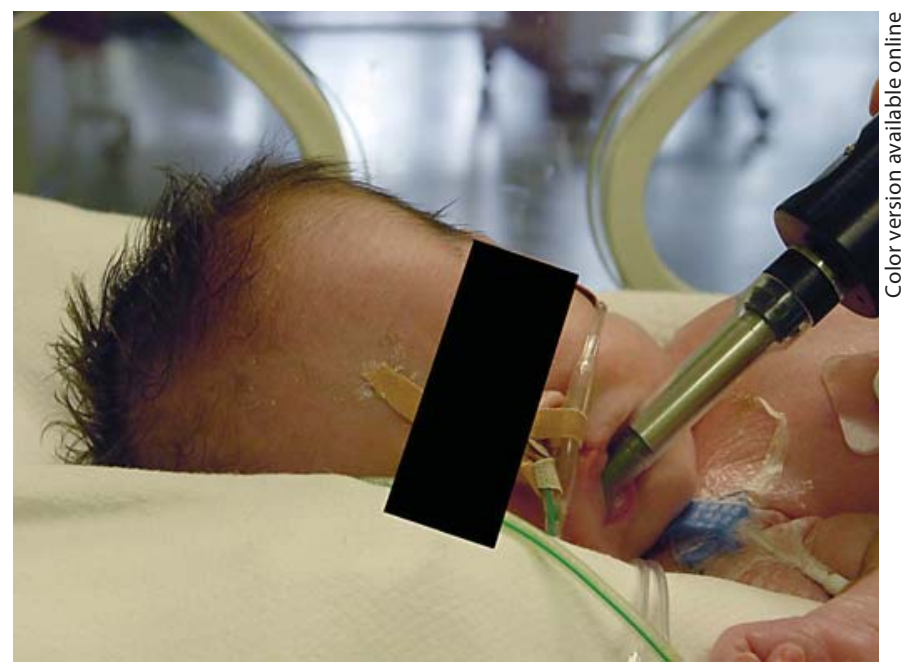

Fig. 1. Example of measurement technique in one of the patients.

The aim of the present study was to determine developmental changes in microcirculation by obtaining microcirculatory parameters in term neonates and children up to the age of 3 years who did not present with compromised respiration or circulation. These data may serve as reference data for critically ill patients.

\section{Methods}

Setting and Patients

This single-center prospective observational study was performed at the surgical ward and the surgical intensive care unit of a level III university children's hospital. Subjects eligible for inclusion were children up to the age of 3 years who did not present with any respiratory or circulatory compromise or signs of dehydration. These were mainly children with congenital malformations or children admitted for small surgical procedures. The age, gender, weight, underlying diagnosis and medication of all patients were recorded in a case report form. Written informed consent was obtained from the parents or guardians. Children with fever, signs of infection, congenital heart disease or lung disease were excluded.

\section{Technique}

The microvascular network was studied with a Cytoscan E-II Backfocus type device (Cytometrics, Philadelphia, Pa., USA) using a $5 \times$ objective. Data were recorded on a Sony DSR-20P digital video recorder. Segments of $5 \mathrm{~s}$ were selected and blindly analyzed offline by the first author. Quantification of the images was accomplished using FCD [3]. The images created were analyzed with the Capiscope software (version 3.7.1.0, KK Technology 1993-2000). For calculation of the FCD, the operator traced out the path of the moving red blood cells within the capillaries. Di- 
viding the total length of the perfused capillaries by the area of the field of view gives the FCD $\left(\mathrm{cm} / \mathrm{cm}^{2}\right)$.

\section{Procedure}

The microcirculation was assessed in the buccal mucosa. The inside of the cheek is readily accessible and intervention was well tolerated in this age group. Moreover, qualitatively good images could be obtained from this site.

In case the patient was scheduled for surgery, measurements were performed either before or at least 1 day after the surgery when there were no signs of postoperative pain or discomfort. All subjects had fasted for at least $30 \mathrm{~min}$ before the measurement. First, saliva was gently removed with gauze. The lens of the OPS imaging device was covered with a disposable sterile cap and was applied to the buccal mucosa without pressure (fig. 1). Images from 3 different regions were obtained and stored on digital videotapes. Segments of $5 \mathrm{~s}$ were selected and computer captured in AVI format. Images had to meet quality criteria, including adequate focus, the absence of saliva and the presence of visible capillaries. Segments that did not meet these criteria were discarded. For every child, FCD values of the different video segments were averaged.

\section{Statistical Analysis}

The data were analyzed using SPSS 15.0. Pearson's product moment correlation coefficient was calculated to establish the linear relationship between postnatal age and FCD. Patients were divided into 4 age groups: $0-7$ days, $8-28$ days, 1-6 months and $2-3$ years old. For comparison between the groups the nonparametric Mann-Whitney test was applied.

\section{Results}

A total of 45 patients were included ( 15 females, 30 males). The age ranges within the different groups were 0-4 days (median 2), 9-22 days (median 15), 36-169 days (median 77) and 1,151-1,416 days (median 1,228). Table 1 shows the diagnoses, the number of patients and the FCD per group.

The median FCD was $8.1 \mathrm{~cm} / \mathrm{cm}^{2}$ (range 7.3-9.4) for 0 - to 7-day-old neonates $(\mathrm{n}=12), 6.9 \mathrm{~cm} / \mathrm{cm}^{2}$ (range 4.7 8.7 ) for 8 - to 28 -day-olds $(\mathrm{n}=10), 7.3 \mathrm{~cm} / \mathrm{cm}^{2}$ (range 6.1 8.8) for 1- to 6-month-olds $(\mathrm{n}=19)$ and $6.7 \mathrm{~cm} / \mathrm{cm}^{2}$ (range 6.5-9.2) for 3-year-olds $(n=4)$ (fig. 2). Figure 3 shows an example of an image.

\section{Discussion}

The main finding of this study was that the FCD of hospitalized infants was highest in the first week of life in term infants. This observation is consistent with findings from a study in premature and term neonates that employed this technique for measurements of the skin [7].

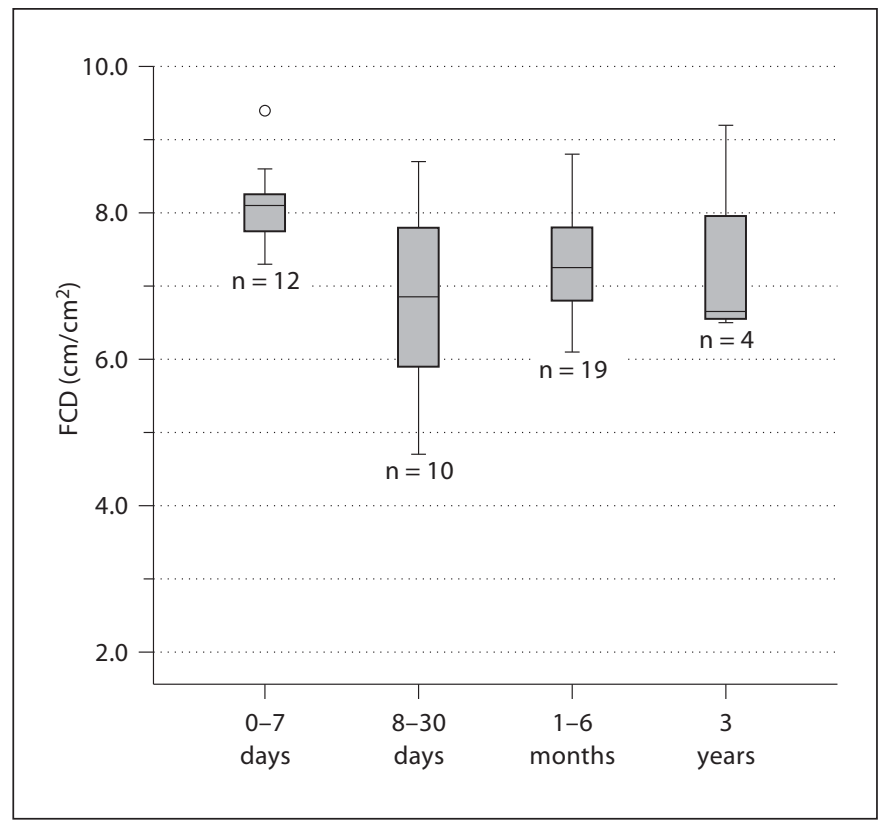

Fig. 2. Boxplot showing FCD for different age groups (0-7 days, $\mathrm{n}=12),(8-30$ days, $\mathrm{n}=10),(1-6$ months, $\mathrm{n}=19)$ and (3 years, $\mathrm{n}=4)$. FCD for neonates younger than 1 week was higher compared with older children $(\mathrm{p}<0.05)$.

Table 1. Diagnoses, number of patients and gender per age group

\begin{tabular}{|c|c|c|c|c|}
\hline $\begin{array}{l}\text { Age } \\
\text { group }\end{array}$ & Diagnosis & $\mathrm{n}$ & $\begin{array}{l}\text { Gender } \\
\mathrm{M} / \mathrm{F}\end{array}$ & $\begin{array}{l}\text { FCD } \\
\mathrm{cm} / \mathrm{cm}^{2}\end{array}$ \\
\hline $\begin{array}{l}0-7 \\
\text { days }\end{array}$ & $\begin{array}{l}\text { total } \\
\text { gastrointestinal } \\
\text { urogenital } \\
\text { meningomyelocele } \\
\text { sacrococcygeal } \\
\quad \text { teratoma }\end{array}$ & $\begin{array}{r}12 \\
9 \\
1 \\
1 \\
1\end{array}$ & $5 / 7$ & $8.1(7.3-9.4)$ \\
\hline $\begin{array}{l}8-28 \\
\text { days }\end{array}$ & $\begin{array}{l}\text { total } \\
\text { gastrointestinal } \\
\text { aplasia cutis }\end{array}$ & $\begin{array}{r}10 \\
9 \\
1\end{array}$ & $6 / 4$ & $6.9(4.7-8.7)$ \\
\hline $\begin{array}{l}1-6 \\
\text { months }\end{array}$ & $\begin{array}{l}\text { total } \\
\text { gastrointestinal } \\
\text { urogenital } \\
\text { sacrococcygeal } \\
\quad \text { teratoma }\end{array}$ & $\begin{array}{r}20 \\
17 \\
2 \\
1\end{array}$ & $15 / 4$ & $7.3(6.1-8.8)$ \\
\hline $\begin{array}{l}3 \\
\text { years }\end{array}$ & $\begin{array}{l}\text { total } \\
\text { gastrointestinal } \\
\text { subcutaneous abscess }\end{array}$ & $\begin{array}{l}4 \\
3 \\
1\end{array}$ & $4 / 0$ & $6.7(6.5-9.2)$ \\
\hline
\end{tabular}

FCD is presented as the median (range). 


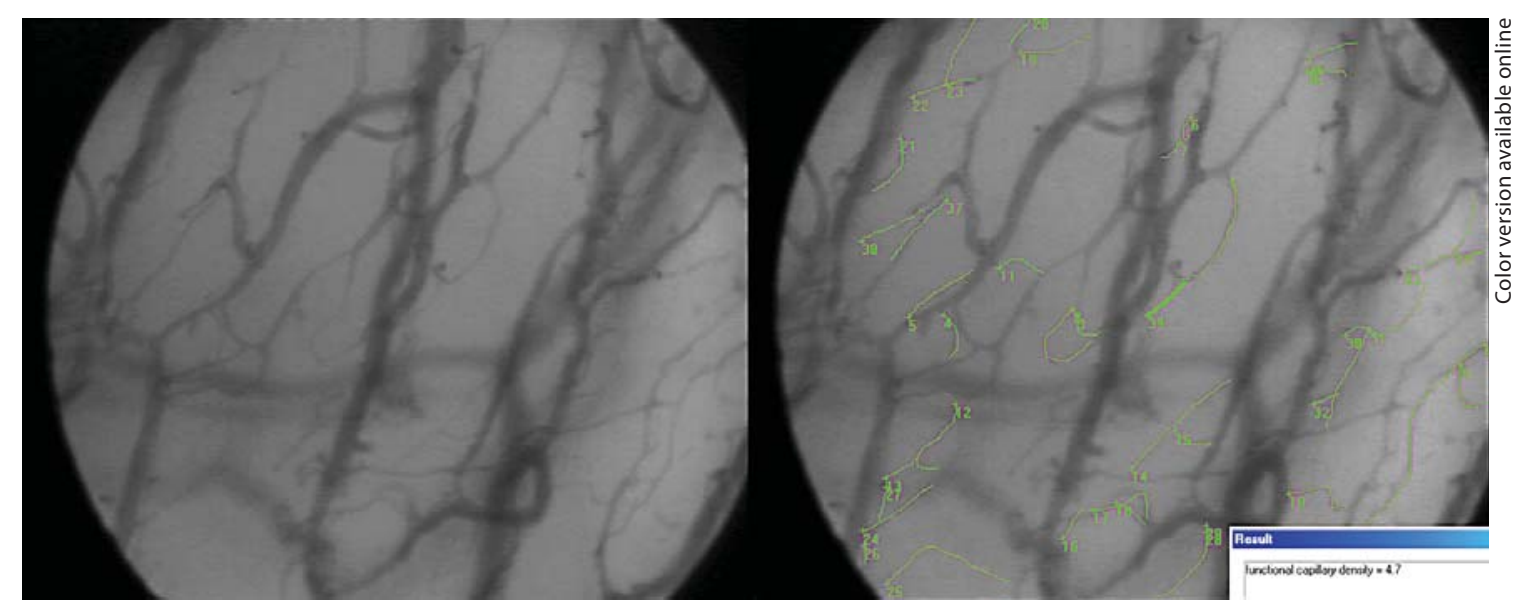

Fig. 3. Example of an image (left) and a tracing of the capillaries (right) to determine the FCD.

Given that these were measurements of the skin, we cannot compare the results other than to conclude that postnatal reduction in FCD may be a generalized phenomenon. It would seem that developmental changes of the microcirculation in early postnatal life are related to adaptation after birth rather than postconceptional age. It is believed that an adult pattern of microvasculature in the skin is reached by the age of 3 months [11]. An important factor in this is cooling; therefore, it is unclear whether the same would apply for other microvascular beds.

The higher FCD in the first week of postnatal life may be related to the notably higher cardiac output in the first week [12]. This is likely because the circulatory alterations that occur following birth impose an added workload (higher volume load and pressure load) on the left ventricle, whereas the pressure load on the right ventricle decreases. The added presence of a 2- to 3 -fold increase in oxygen consumption at birth due to the work of breathing, increased gastrointestinal function with feeding and especially the low temperature environment could be compensated for by higher systemic blood flow. Moreover, the high levels of fetal $\mathrm{Hb}$ reduce the oxygen extraction level [12]. Over the first few postnatal days, resting cardiac output is highest and progressively falls afterwards over a 6- to 8-week period [12].

Several other cardiovascular changes found during the initial weeks following birth could account for the reduction in FCD observed here. Wu et al. [13] found an increase in skin peripheral vascular resistance during the first 7 days of life and the neonatal period that correlated with a decreasing blood flow using electrocapacitance plethysmography. However, this technique gives infor- mation about total blood flow and does not distinguish between flow and vessel density. Beinder et al. [14] suggested that myogenic activity in skin arterioles increases with advancing age, a mechanism that might explain the reduced FCD observed here. Finally, the $\mathrm{Hb}$ level is closely correlated to FCD $[7,15]$ and has been found to decrease during the 5- to 6-week postnatal period. Although we did not find a progressive drop in FCD after the age of 1 week, decreasing Hb levels may have played a role in the developmental change in FCD during the first month of life. In this study, we were not able to correlate $\mathrm{Hb} \mathrm{lev-}$ els with FCD.

Microvascular abnormalities can be frequently observed in critically ill patients and may play an important role in the pathogenesis of organ dysfunction. Especially due to the limitations of monitoring cardiac output and tissue perfusion $[16,17]$ in young children, this noninvasive technique might become an important additive bedside tool to the currently used monitoring tools in critically ill neonates and children.

The technique was well tolerated in children under the age of 6 months or over the age of 3 years. In children between 6 months and 2 years of age, it was often impossible to perform measurements because these patients were not compliant. Therefore, subjects in this age range could not be included in our study because it was too difficult to obtain stable images over a long period of time that fulfilled the quality criteria [8]. This is because the probe is very sensitive to movements.

To our knowledge, this study presents the first observations of the buccal microcirculation in children with a presumably normal cardiovascular system. These data 
can serve as reference data for critically ill children and are relevant for future studies of the microcirculation in children. Our study also shows the feasibility of the technique in young children. The application in children who are not sedated is limited by the lack of compliance in younger age groups. Therefore, we recommend using this technique in sedated patients. This technique is a promising bedside tool for future clinical application. Further research is needed to investigate older age groups to determine if the trend observed in our study is limited to the neonatal period or whether developmental changes can be observed throughout childhood.

\section{Conclusion}

FCD of the buccal mucosa decreases after the first week of neonatal life. More research is needed to investigate the development of vascular resistance and other cardiovascular parameters after birth, which might underlie the developmental changes observed in the microcirculation of children.

\section{References}

1 Fagrell B, Intaglietta M: Microcirculation: its significance in clinical and molecular medicine. J Intern Med 1997;241:349-362.

-2 Sakr Y, Dubois MJ, De Backer D, Creteur J, Vincent JL: Persistent microcirculatory alterations are associated with organ failure and death in patients with septic shock. Crit Care Med 2004;32:1825-1831.

3 Groner W, Winkelman JW, Harris AG, Ince C, Bouma GJ, Messmer K, Nadeau RG: Orthogonal polarization spectral imaging: a new method for study of the microcirculation. Nat Med 1999;5:1209-1212.

$\checkmark 4$ De Backer D, Creteur J, Preiser JC, Dubois MJ, Vincent JL: Microvascular blood flow is altered in patients with sepsis. Am J Respir Crit Care Med 2002;166:98-104.

5 Norman M, Herin P, Fagrell B, Zetterstrom $\mathrm{R}$ : Capillary blood cell velocity in full-term infants as determined in skin by videophotometric microscopy. Pediatr Res 1988;23: 585-588.
6 Jahnukainen T, Lindqvist A, Jalonen J, Kero P, Valimaki I: Reactivity of skin blood flow and heart rate to thermal stimulation in infants during the first postnatal days and after a two-month follow-up. Acta Paediatr 1996; 85:733-738.

7 Kroth J, Weidlich K, Hiedl S, Nussbaum C, Christ F, Genzel-Boroviczeny O: Functional vessel density in the first month of life in preterm neonates. Pediatr Res 2008;64:567-571.

$\checkmark$ Top AP, Ince C, van Dijk M, Tibboel D: Changes in buccal microcirculation following extracorporeal membrane oxygenation in term neonates with severe respiratory failure. Crit Care Med 2009;37:1121-1124.

9 Genzel-Boroviczeny O, Seidl T, Rieger-Fackeldey E, Abicht J, Christ F: Impaired microvascular perfusion improves with increased incubator temperature in preterm infants. Pediatr Res 2007;61:239-242.

10 Hubble SM, Kyte HL, Gooding K, Shore AC: Variability in sublingual microvessel density and flow measurements in healthy volunteers. Microcirculation 2009;16:183-191.

$\checkmark 11$ Perera P, Kurban AK, Ryan TJ: The development of the cutaneous microvascular system in the newborn. Br J Dermatology 1970;82: 86-91.
12 Stopfkuchen H: Changes of the cardiovascular system during the perinatal period. Eur J Pediatr 1987;146:545-549.

13 Wu PY, Wong WH, Guerra G, Miranda R, Godoy RR, Preston B, Schoentgen S, Levan NE: Peripheral blood flow in the neonate. 1. Changes in total, skin, and muscle blood flow with gestational and postnatal age. Pediatr Res 1980;14:1374-1378.

14 Beinder E, Trojan A, Bucher HU, Huch A, Huch R: Control of skin blood flow in preand full-term infants. Biol Neonate 1994;65: 7-15.

15 Nadeau RG, Groner W: The role of a new noninvasive imaging technology in the diagnosis of anemia. J Nutr 2001;131:1610S$1614 \mathrm{~S}$.

16 Ceneviva G, Paschall JA, Maffei F, Carcillo JA: Hemodynamic support in fluid-refractory pediatric septic shock. Pediatrics 1998; 102:e19.

17 de Boode WP: Cardiac output monitoring in newborns. Early Hum Dev 2010;86:143-148. 